This item was submitted to Loughborough's Research Repository by the author.

Items in Figshare are protected by copyright, with all rights reserved, unless otherwise indicated.

\title{
Effect of physical activity, nutritional education, and consumption of extra virgin olive oil on lipid, physiological and anthropometric profiles in a pediatric population
}

\section{PLEASE CITE THE PUBLISHED VERSION}

http://dx.doi.org/10.1123/jpah.2014-0236

\section{PUBLISHER}

(c) Human Kinetics

\section{VERSION}

VoR (Version of Record)

\section{PUBLISHER STATEMENT}

This work is made available according to the conditions of the Creative Commons Attribution-NonCommercialNoDerivatives 4.0 International (CC BY-NC-ND 4.0) licence. Full details of this licence are available at: https://creativecommons.org/licenses/by-nc-nd/4.0/

\section{LICENCE}

CC BY-NC-ND 4.0

\section{REPOSITORY RECORD}

Muros, Jose Joaquin, Mikel Zabala, Maria J. Oliveras-Lopez, Paula R. Bouzas, Emily C. Knox, Jose A. RufianHenares, and Herminia L.-G. de la Serrana. 2019. "Effect of Physical Activity, Nutritional Education, and Consumption of Extra Virgin Olive Oil on Lipid, Physiological and Anthropometric Profiles in a Pediatric Population". figshare. https://hdl.handle.net/2134/20887. 
Muros (ijmuros@ugr.es) and Rufián-Henares are with the Dept of Food Science, School of Pharmacy, University of Granada, Granada, Spain. Zabala is with the Dept of Physical Education, School of Sport Science, University of Granada, Granada, Spain. Oliveras-López and Bouzas are with the Dept of Molecular Biology and Biochemistry Engineering, School of Sciences, University Pablo de Olavide, Seville, Spain. Knox is with the School of Sport, Exercise, and Health Sciences, Loughborough University, Leicestershire, United Kingdom. López-García de la Serrana is with the Dept of Nutrition and Food Science, University of Granada, Granada, Spain.

\title{
Effect of Physical Activity, Nutritional Education, and Consumption of Extra Virgin Olive Oil on Lipid, Physiological, and Anthropometric Profiles in a Pediatric Population
}

\author{
José Joaquín Muros, Mikel Zabala, María Jesús Oliveras-López, Paula Rodríguez Bouzas, \\ Emily Knox, José Ángel Rufián-Henares, and Herminia López-García de la Serrana
}

\begin{abstract}
Background: The aim of this study was to determine the effects of nutritional education and vigorous physical activity on healthrelated parameters. Methods: The sample group consisted of 134 children from 5 rurally located schools. Participants were divided between 5 different experimental groups: control group (CG), physical activity group (PA), nutritional education group (NE), combined intervention group $(\mathrm{PA}+\mathrm{NE})$, and a combined intervention group with additional substitution of normally used oil for extra virgin olive oil (EVOO; PA+NE+EVOO). The intervention consisted of 60 minute sessions of physical activity held twice a week as well as nutritional education sessions held over 6 months. Results: Students in the groups receiving physical activity reduced their fat percentage and increased their muscle mass post intervention. At posttest the lipid profile improved in all intervention groups. The proportion of macronutrients and dietary cholesterol improved in the groups receiving nutritional education. The posttest comparison showed significantly lower fat percentage, sum of skinfolds and waist circumference in NE relative to CG and PA relative to CG. Diastolic blood pressure and glycaemia were significantly lower in PA+NE+EVOO relative to CG. Conclusion: A school-based program consisting of nutritional education or nutritional education plus a physical activity program showed a positive effect on healthrelated parameters in children.
\end{abstract}

\section{Keywords: sport, health}

Physical inactivity is considered to be one of the main threats to public health in the 21 st century. ${ }^{1}$ Physical activity is negatively associated with overweight and obesity, and positively associated with cardiovascular health in young people. ${ }^{2}$ Increases in aerobic capacity are inversely related with improvements to specific health parameters in youth, including the lipid profile, ${ }^{3}$ insulin resistance, ${ }^{4}$ fat mass $^{5}$ and parameters associated with metabolic symdrome. ${ }^{6}$

Nutrition has been labeled as one of the main modifiable determinants of chronic diseases. ${ }^{7}$ Establishing healthy eating habits during childhood and adolescence is important, since it has been shown that food preferences and eating habits are established in early childhood and can persist into adulthood. ${ }^{8}$ Research suggests that many children consume sugar, salt and saturated fats in excess of recommended amounts and at the same time fail to consume the recommended amounts of fresh fruit and vegetables. Lifestyle changes away from the traditional Mediterranean state in the Western world ${ }^{9}$ have highlighted the need to promote the traditional Mediterranean diet (MD) among pupils in schools with a view to improving dietary habits. A large number of studies have demonstrated the beneficial effects of specific components of the MD, such as olive oil on weight loss, ${ }^{10}$ abdominal obesity, ${ }^{11}$ insulin resistance, ${ }^{12}$ risk of diabetes mellitus, ${ }^{13}$ and cardiovascular diseases. ${ }^{14}$

Following on from studies, which have demonstrated improvements in some physiological risk factors ${ }^{15}$ using vigorous physical training programs with obese children and adolescents during after-school hours, the American Heart Association has recognized the importance of prevention and treatment. In addition, it is important to involve parents in healthy interventions, as parents have a strong influence on the eating habits of young people and adolescents. ${ }^{16}$

The aim of our study was to investigate the effects of 4 experimental conditions and 1 no intervention control group (CG) on health- related parameters, such as the lipid, physiological and anthropometric profiles of children. The experimental condition groups were as follows: Group received a physical activity intervention (PA), group received a nutritional intervention $(\mathrm{NE})$, group received both $(\mathrm{PA}+\mathrm{NE})$, and group received $\mathrm{PA}+\mathrm{NE}$ and in addition substitute their usual cooking oil with extra virgin olive oil (EVOO) during the last month of the intervention.

\section{Methods}

\section{Participants}

Five schools were selected from Granada, Spain. All schools were in a similar rural environment and had the same socioeconomic status. Students were aged between 10 and 11 years $($ mean $=10.7 \pm 0.5)$. The opportunity to participate was offered to the parents of all the children regardless of body mass index (BMI). The sample was randomized at school-level into 5 groups; each school belonged to a different group and received a different intervention. The program consisted of 1 group which did not receive any intervention (CG; $\mathrm{n}=41,20$ boys and 21 girls), 1 group which received a physical activity intervention (PA; $\mathrm{n}=$ 28,13 boys and 15 girls), 1 group in which parents and pupils received 
nutritional education sessions ( $N E ; n=21,10$ boys and 11 girls), and 1 group which received both of the above interventions $(\mathrm{PA}+\mathrm{NE} ; \mathrm{n}=$ 25,14 males and 11 girls). The final group received the same intervention as $\mathrm{PA}+\mathrm{NE}$ and also replaced the oil that they normally consumed with EVOO during the final month of the intervention (PA+NE+EVOO; $\mathrm{n}=20,11$ boys and 9 girls). Out of a total of 242 pupils, 162 agreed to participate $(66.9 \%)$, and 135 completed the intervention (55.8\%). A total of 51.2\%, 39.2\%, 23.8\%, 32\% and $40 \%$ of the pupils presented as overweight or obese in CG, PA, NE, PA+NE, and $\mathrm{PA}+\mathrm{NE}+\mathrm{EVOO}$, respectively. Overweight or obesity was defined according to international criteria. ${ }^{17}$

The Tanner and Whitehouse ${ }^{18}$ stage of sexual maturity was established by a trained researcher of the same gender as the young person via brief observation of the mammary development in females and genital development in males. All participants were found to be in stages 1 or 2 with no significant differences between the sexes for any of the studied parameters. This aspect was therefore not taken into account when forming the intervention group and the control group.

All children were healthy and were not receiving any medical treatment. All the participants took part voluntarily in accordance with the Declaration of Helsinki regarding ethical research. The bioethical committee of the University of Granada for human research approved the study. Informed consent was also obtained from all of the children's parents.

\section{Procedure}

This study examined the health benefits of physical exercise and nutritional intervention both separately and in combination and further investigated the effects of EVOO consumption. The intervention consisted of 60 minutes sessions of physical activity held twice a week as well as nutritional education sessions. The study was carried out over 6 months between January and June 2012. The intervention consisted of 60 -minute sessions of vigorous extracurricular physical activity (VEPA) [80\% of maximum heart rate (MHR) for 35 to 40 minutes, $60 \%$ to $70 \%$ of the MHR for 10 to 15 minutes, and $50 \%$ to $60 \%$ for 5 to 10 minutes] twice a week. Physical activity was controlled by means of heart rate monitoring (Polar RS800cx pulsometer). The aim of the training sessions was to improve aerobic capacity using physical activities specifically targeted for health gains such as motor skills, games and sports. Play was used in all the activities to motivate the students and achieve the desired level of physical activity. All games and tasks were designed and developed by a group of experts in education and sports science and were directed by the same supervisor. The present methodology has been put into practice in previous studies and was adapted to the age of the participants for this study. Only students who attended more than $75 \%$ of sessions (more than 36 sessions) were included in the intervention group; those not completing the sessions were excluded from the study. Out of a total of 72 pupils, 61 completed over $75 \%$ of the sessions $(84.7 \%)$.

The nutritional education sessions informed participants about the benefits of a MD (high fruit, vegetable, legumes, fish, cereals, unsaturated to saturated fat ratio, and low meat, meat products and dairy products) and lifestyle. Nutritional education involved both parents and students. For parents, there were 6 classes of nutritional education, each lasting approximately 2 hours. One session was provided each week for the first 6 weeks of intervention. Either 1 or both parents could attend the sessions. For children, there were 2 nutritional education sessions during school hours (tutorial hours), each lasting about 1 hour. One session was held each week for the first 2 weeks of intervention. It was compulsory for pupils to attend both nutrition sessions held during school time. Seventy-three of the 75 initial participants attended these sessions (97.3\%). Pupils were considered fit to participate in the study if they participated in over $75 \%$ of the school physical activity sessions, attended the 2 sessions on nutritional education, and had at least 1 parent attend over $75 \%$ of the parental educational sessions. Out of a total of 75 pupils, 58 fulfilled these conditions $(77.3 \%)$.

In $\mathrm{PA}+\mathrm{NE}+\mathrm{EVOO}$ group each pupil's parent received $2 \mathrm{~L}$ of EVOO per week in the last month of intervention. The parents formally agreed to substitute their normal oil consumption with this oil every time they cooked.

During the intervention period, CG continued with their usual activities. They participated in pre and posttest measures only to provide a comparison for the other groups and enable identification of changes in any parameters. The pretest and posttest data shown in Tables 1-3 illustrate the results obtained for pupils completing the intervention.

\section{Measures}

The following variables were measured during pretest and the posttest:

\section{Aerobic Capacity.}

Maximal oxygen uptake $\left(\mathrm{VO}_{2} \mathrm{max}\right)$ was estimated using a $20 \mathrm{~m}$ incremental-maximum shuttle run field test, employing the equation proposed by Ruiz et al. ${ }^{19}$ The shuttle run test involves running to and from between 2 lines placed $20 \mathrm{~m}$ apart. Participants start at an initial velocity of $8.5 \mathrm{kph}$, and increase their speed by $0.5 \mathrm{kph}$ for every $20 \mathrm{~m}$ covered as indicated by an audio recording played on a validated CDROM. The test concludes when the subject is unable to reach the line on 2 consecutive occasions at the speed demanded by the audio recording.

\section{Anthropometric Data.}

Guidelines of the International Society for the Advancement of Kinanthropometry (ISAK) ${ }^{20}$ were followed. All anthropometric measurements were carried out at the same place by an ISAK-certified level II anthropometrics researcher. The following instruments were used: GPM Stadiometer ( $\pm 1 \mathrm{~mm}$ accuracy); Tefal scale $( \pm 50 \mathrm{~g}$ accuracy); Holtain skinfold compass ( $\pm 1 \mathrm{~mm}$ accuracy); Holtain caliper ( $\pm 1 \mathrm{~mm}$ accuracy); Holtain flexible metallic metric belt $( \pm 1$ $\mathrm{mm}$ accuracy). The following measurements were taken: height, weight, skinfolds (triceps, biceps, subscapular, suprailiac, supraspinal, abdominal, thigh, and calf), perimeters (waist, hip, relaxed biceps, flexed and contracted biceps, thigh and calf), and diameters (bicondylar humerus, bistiloid and bicondylar femur). The body mass index (BMI) was calculated from height and weight. We compared the results gathered from the sum of the 8 skinfolds (triceps, biceps, subscapular, suprailiac, supraspinal, abdominal, thigh, and calf), fat percentage using the Slaughter equation ${ }^{21}$ and mass percentage using the Poortman equation. ${ }^{22}$

\section{Blood Biochemistry.}

We used venous blood analysis to determine the health-related biochemical components. The analysis was performed in the morning after a 12-hour fasting period. The samples were stored in the dark in containers with ice and processed within the hour after extraction. Plasma was separated by centrifugation of the blood samples at 1500 $\mathrm{rpm}$ for $20 \mathrm{~min}$ at 18 to $25^{\circ} \mathrm{C}$. The following parameters were measured: glycaemia $(\mathrm{GL})(\mathrm{mg} / \mathrm{dl})$, total cholesterol (TC) $(\mathrm{mg} / \mathrm{dl})$, HDL cholesterol (cHDL) (mg/dl), LDL cholesterol (cLDL) (mg/dl) and triglycerides (TG) (mg/dl). TC, cHDL and TG were determined using commercially available enzymatic colorimetric assays (Sigma 
Diagnostics, St. Louis, MO) on an automated ACE analyzer. cLDL was calculated by the Friedewald equation. ${ }^{23}$

\section{Blood Pressure.}

Both systolic and diastolic blood pressure measurements were taken using an OMROM M7 monitor (Omrom Health Care, Ukyo-ku, Kyoto, Japan). The cuff was placed carefully on the right arm, following the recommendations of the European Hypertension Society, and the method stipulated by international guidelines. ${ }^{24}$ Resting blood pressure was determined in situ on the morning (casual blood pressure) of the pre- and posttests with measurements taken at the same time of day on each occasion. Participants were instructed to sit quietly for $5 \mathrm{~min}$ with their right arm rested at heart level and their feet flat on the floor. Three blood pressure readings were taken at 5, 7, and $9 \mathrm{~min}$, and the cuff was then removed. An average blood pressure measure was calculated.

\section{Dietary Changes.}

All the pupils completed 2 dietary intake diaries, one before the intervention and another after finishing it. Diaries covered 3 consecutive days and included at least 1 weekend day. All pupils and their parents were instructed to fill out the forms using weights and home measurements, noting all the food they consumed both inside and outside the home. DietSource 3.0 was used to evaluate macronutrients.

\section{Analysis}

For all measures the investigators were blinded to the grouping. Normality of the data were analyzed using the Shapiro-Wilk test. A series of 2 (gender) $\times 5$ (group) ANOVAs assessed gender differences in the outcome variables at pre and post time points. There was no significant main effect of gender on any of the tested outcome variables at pre- $(P>.05)$ or posttest $(P>.05)$. Interactions between groups were also not significant at pretest $(P>.05)$. Based on these results further analyses were not stratified by gender. We performed $\mathrm{T}$ tests and Wilcoxon tests for 2 related samples to compare aerobic capacity, anthropometric parameters, blood composition, blood pressure, and dietary changes. Intervention effects between-groups for all parameters were assessed using 2-way ANOVA's and post hoc with Bonferroni correction. This analysis allowed for the comparison of changes in baseline scores to those measured posttest while adjusting for the type of intervention (ie, group/treatment) and baseline scores (ie, time). All analyses were conducted using the SPSS 19.0 statistics package. The level of significance was established at .05 .

\section{Results}

Age, sex, BMI, fat percentage, overweight/obesity status and blood composition of the study participants at baseline are shown in Table 1.

\section{Maximal Oxygen Uptake}

We found no significant differences between groups at pretest. Neither CG nor NE demonstrated any significant differences between their preand posttest results; however, all groups which incorporated physical activity (PA, $\mathrm{PA}+\mathrm{NE}$ and $\mathrm{PA}+\mathrm{NE}+\mathrm{EVOO})$ showed significant improvements $(P=.000, .007$, and .000 , respectively $)$ after intervention (Table 2). No significant differences in maximal oxygen uptake were found between groups.

$\backslash$ insert table 1 and $2 \backslash$

\section{Anthropometric Parameters}

BMI significantly increased in group CG only $(P=.008)$. CG showed a significant increase in the sum of the 8 skinfolds and in fat percentage at posttest. Conversely, we observed a significant decrease in the sum of the skinfolds and fat percentage in $\mathrm{PA}, \mathrm{PA}+\mathrm{NE}$ and $\mathrm{PA}+\mathrm{NE}+\mathrm{EVOO}$. At the same time PA and PA+NE+EVOO significantly increased their muscle percentage ( $P=.007$ and .018 , respectively). Accordingly, these groups were the only ones with a significant decrease in waist circumference and waist-hip ratio (WHR) when compared pre- and posttest (values Table 2). 2-way ANOVA revealed no interaction effect between groups. Post hoc revealed significant differences in BMI between CG and NE (Table 3). In the case of fat percentage, sum of the 8 skinfolds and waist circumference, significant differences were identified between CG-NE and CG-PA+NE $(P<.05)$.

$\backslash$ insert table $3 \backslash$

\section{Blood Pressure and Blood Composition}

Table 4 shows the changes in blood pressure and blood composition between pre- and posttest values. Systolic blood pressure (SBP) increased in $\mathrm{CG}$ and decreased in other groups, though significant reductions occurred only in $\mathrm{PA}$ and $\mathrm{PA}+\mathrm{NE}+\mathrm{EVOO}(P=.005$ and .017 , respectively). Diastolic blood pressure (DBP) increased in $\mathrm{CG}$, was unchanged in NE and decreased in the other 3 groups, with significant reductions in $\mathrm{PA}$ and $\mathrm{PA}+\mathrm{NE}(P=.021$ and .007 , respectively). $\mathrm{PA}, \mathrm{PA}+\mathrm{N}$ and $\mathrm{PA}+\mathrm{NE}+\mathrm{EVOO}$ achieved significant reductions in GL $(P=.002, .031$ and .035$)$ and TC $(P=.000)$, with no significant changes in the other groups. $\mathrm{PA}+\mathrm{NE}+\mathrm{EVOO}$ was the only group showing significant changes in cHDL $(P=.047)$. The cLDL level increased in $\mathrm{CG}$ and decreased in all other groups with significant reduction in $\mathrm{PA}, \mathrm{PA}+\mathrm{NE}$ and $\mathrm{PA}+\mathrm{NE}+\mathrm{EVOO}(P=.000, .000$, and .022 , respectively). TG showed a significant reduction in $\mathrm{PA}, \mathrm{NE}$ and $\mathrm{PA}+\mathrm{NE}+\mathrm{EVOO}(P=.004, .030$, and .043 respectively $)$ while the other groups showed no significant changes. 2-way ANOVA analysis confirmed that differences were only influenced in the case of DBP. However, Glycaemia was influenced by group, intervention time and the interaction between both of them, suggesting that baseline differences accounted for some of our findings for this outcome. The Bonferroni test showed a significant difference in DBP and glycaemia between $\mathrm{CG}$ and $\mathrm{PA}+\mathrm{NE}+\mathrm{EVOO}$.

$\backslash$ insert table $4 \backslash$

\section{Dietary Intake in 72-Hour Regimen}

The calorie profile of the diets analyzed before intervention showed an excess of proteins and fats, and a lack of carbohydrates. This is inadequate to meet the recommendations; $10 \%$ to $15 \%$ proteins, $30 \%$ to $35 \%$ fats, and $50 \%$ to $60 \%$ carbohydrates, for the Spanish population. Cholesterol levels were higher than recommended $(<300$ $\mathrm{mg}$ /day) for all groups. Throughout the intervention, NE, PA+NE and $\mathrm{PA}+\mathrm{NE}+\mathrm{EVOO}$ experienced changes in calorie profile, making it more congruent with the Spanish recommended levels. At posttest NE, $\mathrm{PA}+\mathrm{NE}$ and $\mathrm{PA}+\mathrm{NE}+\mathrm{EVOO}$ showed significant reductions in cholesterol $(P=.000, .001$, and .000 respectively), bringing values closer to these stated by the recommendations (Table 4). No significant differences were found between groups. 


\section{Discussion}

The main findings of the current study suggest that a combination of physical activity and nutritional education conducted over 6 months within the school environment and, involving both parents and pupils, can have an influence on health by promoting positive lifestyle changes.

Many papers have described intervention programs targeting obesity within children. Such interventions tend to focus on physical activity, sometimes in combination with controlled diets or nutritional education. However, it is noteworthy that most of the studies are performed with an overweight or obese population. In contrast, the current study focuses on prevention with a sample which includes normal weight, overweight and obese children.

Vigorous physical activity can reduce overall body fat while simultaneously increasing muscle mass. A child can therefore improve their body composition with no significant reduction in BMI. ${ }^{25} \mathrm{We}$ therefore suggest that other body composition indices may be more appropriate for use in future studies.

Previous studies have shown that a decreased level of aerobic fitness in children is inversely associated with body fatness, impairment of several cardiovascular disease risk factors and hypertension. ${ }^{26}$ Our research shows that the pupils who increased their vigorous physical activity also experienced reductions in body fatness, $\mathrm{SBP}$ and DBP, and parameters related with cardiovascular risk (eg, CT, cLDL, and TG). Interestingly, aerobic fitness level is still not well recognized as a screening tool in pediatric populations. ${ }^{27}$

The decreases in SBP and DBP observed in our study, occurred only in the groups receiving physical activity and nutritional education which corresponds with other studies using similar children. ${ }^{28}$ To our knowledge, just 1 recent paper $^{29}$ describes improvements in systolic and diastolic blood pressure in 9-year-old children after a physical activity intervention at school.

Levels of serum lipids obtained after intervention in the current study are similar to those obtained by Ben Ounis et al. ${ }^{30}$ This study also combined physical activity and dietary restriction with a group of 24 obese adolescents between the ages of 12 and 14 years and found reductions in TC and cLDL over a 2-month period. In addition, significant improvements to cHDL and TG were observed. Another recent study ${ }^{31}$ found improvements in plasma glucose, insulin, cLDL and triglycerides of overweight prepubertal children by introducing a physical-activity program, a parental dietary-modification program, or a combination of the two. Present findings suggest that physical activity may overcome the deleterious effects of unhealthy dietary habits. Similar conclusions were made by Cuenca-Garcia et $\mathrm{al}^{32}$ using an adolescents sample.

The dietary profiles developed using diets analyzed at pretest were clearly unbalanced and contained a high percentage of calories obtained from proteins and fats, and a low percentage of calories obtained from carbohydrates. This situation is typical in Spain and other countries whose dietary habits could be classified as Mediterranean. ${ }^{33}$ In our study, the high intake of fats, proteins and cholesterol, and low intake of carbohydrates and fiber replicates findings from other studies conducted in Spain. ${ }^{34}$ This is also consistent with the general tendency in the Spanish population to consume high amounts of meat and meat products.

Research surrounding the Mediterranean diet is of interest for public health. A large number of studies have demonstrated the beneficial effects of specific components of the Mediterranean diet on weight loss, ${ }^{35}$ abdominal obesity,${ }^{36}$ insulin resistance,,${ }^{11}$ risk of diabetes mellitus $^{37}$ and cardiovascular diseases. ${ }^{14}$ One of the possible mechanisms through which the MD may influence these diseases is via the influence of high antioxidant content on $\beta$-cell dysfunction, and the inflammatory effects of high levels of vitamins, minerals, antioxidants and unsaturated fats (especially olive oil). ${ }^{38}$ There is accumulating evidence to suggest that olive oil in human diets may increase cHDL and its main apolipoprotein A1. ${ }^{39}$ Intervention studies have demonstrated that plasma lipids can be modified by the consumption of EVOO, but that the extent of such modification depends on the composition and amount of active minor components. Several papers have reported an increase in cHDL levels and a decrease of the LDL/HDL ratio $^{40}$ after EVOO intake, especially with high polyphenol content. In the current study the group which replaced the oil that they normally consumed with EVOO showed improved cHDL levels. Another randomized trial also found the traditional MD supplemented with either EVOO or nuts having benecial effects on blood pressure. ${ }^{41}$ Our study showed similar results with the group which replaced the oil that they normally consumed with EVOO showing decreased SBP levels.

The school environment is recognized as an important setting for health promotion interventions for children. Reviews have found that well-designed and well-implemented school-based interventions can have positive effects on children's nutrition and physical activity behaviors. ${ }^{42}$ Another important factor in childhood health promotion, especially for younger children, is the use of parents as prominent role models. The current study encouraged parental involvement. Other authors such as Ventura \& Birch $^{43}$ have found evidence of strong relationships between parenting practices and their children's eating, physical activity, and weight status. The promotion of effective parenting therefore appears critical for prevention.

The results of this study provide evidence that a 6 months schoolbased program incorporating vigorous physical activity, nutritional education for children and parents, and replacement of normally used oils with EVOO, can improve health-related parameters in children. Physical activity improved maximal oxygen uptake, anthropometric parameters and biochemical markers of these school-children. In contrast, nutritional education was only associated with improvements in some biochemical parameters such as triglycerides. The consumption of EVOO maximized the positive effects seen on cHDL. Finally, the consumption of EVOO improved glycaemia and DBP compared with the normal lifestyle group.

\section{Acknowledgments}

The authors wish to thank the attitude and assistance of all the young people participating in the study, and we are grateful to their parents and teachers for their collaboration. This study was supported by Mapfre Foundation and was partially supported by project MTM2010-20502 of Dirección General de Investigación and Gestión del Plan Nacional I+D+I and grant FQM-307 of Consejería de Innovación de la Junta de Andalucía, all in Spain.

\section{References}

1. Blair SN. Physical inactivity: the biggest public health problem of the 21 st century. Br J Sports Med. 2009;43:1-2. PubMed

2. Andersen LB, Bugge A, Dencker M, Eiberg S, El-Naaman B. The association between physical activity, physical fitness and development of metabolic disorders. Int $J$ Pediatr Obes. 2011;6:29-34. PubMed doi:10.3109/17477166.2011.606816

3. Llorente-Cantarero FJ, Pérez-Navero JL, Benitez-Sillero JD, MuñozVillanueva MC, Gil-Campos M. Evaluation of metabolic risk in prepubertal girls versus boys in relation to fitness and physical activity. Gend Med. 2012;9:436-444. PubMed doi:10.1016/j.genm.2012.08.006 
4. Berman LJ, Weigensberg MJ, Spruijt-Metz D. Physical activity is related to insulin sensitivity in children and adolescents, independent of adiposity: a review of the literature. Diabetes Metab Res Rev. 2012;28:395-408. PubMed doi:10.1002/dmrr.2292

5. Pahkala K, Hernelahti M, Heinonen OJ, et al. Body mass index, fitness and physical activity from childhood through adolescence. $\mathrm{Br} J$ Sports Med. 2013;47:71-77. PubMed doi:10.1136/bjsports-2011090704

6. Christodoulos AD, Douda HT, Tokmakidis SP. Cardiorespiratory fitness, metabolic risk, and inflammation in children. Int J Pediatr. Article. 2012;ID 270515

7. World Health Organisation. Diet, Nutrition and the Prevention of Chronic Diseases: Report of a Joint WHO/FAO Expert Consultation. Geneva: WHO, WHO Technical Report Series no. 916; 2003.

8. Craigie AM, Lake AA, Kelly SA, Adamson AJ, Mathers JC. Tracking of obesity-related behaviours from childhood to adulthood: a systematic review. Maturitas. 2011;70:266-284. PubMed doi:10.1016/j.maturitas.2011.08.005

9. Lazarou C, Panagietakos DB, Matalas AL. Level of adherence to Mediterranean diet among children from Cyprus; the Cykids study. Public Health Nutr. 2009;12:991-1000. PubMed doi:10.1017/S1368980008003431

10. Bonnacio M, Bonanni AE, Di Castelnovo A, et al. Low income is associated with poor adherence to a Mediterranean diet and higher prevalence of obesity: cross-sectional results from the Moli-sani study. BMJ. 2012;2:1-9.

11. Bos MB, de Vries JH, Feskens EJ, et al. Effect of a high monounsaturated fatty acids diet and a Mediterranean diet on serum lipids and insulin sensitivity in adults with mild abdominal obesity. Nutr Metab Cardiovasc Dis. 2010;20:591-598. PubMed doi:10.1016/j.numecd.2009.05.008

12. Tzima N, Pitsavos C, Panagiotakos DB, et al. Mediterranean diet and insulin sensitivity, lipid profile and blood pressure levels, in overweight and obese people; the Attica study. Lipids Health Dis. 2007;19:6-22. PubMed

13. de Lorgeril M. PREDIMED trial: Mediterranean diet may reduce the risk of type 2 diabetes. Evid Based Med. 2011;16:152-153. PubMed doi:10.1136/ebm1400

14. Domínguez LJ, Bes-Rastrollo M, de la Fuente-Arrillaga C, et al. Similar prediction of decreased total mortality, diabetes incidence or cardiovascular events using relative- and absolute-component Mediterranean diet score: The SUN cohort. Nutr Metab Cardiovasc Dis. 2013;23:451-458. PubMed doi:10.1016/j.numecd.2011.10.009

15. Pate RR, O'Neill JR. Summary of the American Heart Association scientific statement: promoting physical activity in children and youth: a leadership role for schools. $J$ Cardiovasc Nurs. 2008;23:44-49. doi:10.1097/01.JCN.0000305056.96247.bb

16. Pearson N, Biddle SJH, Gorely T. Family correlates of fruit and vegetable consumption in children and adolescents: a systematic review. Public Health Nutr. 2008;12:267-283. PubMed doi:10.1017/S1368980008002589

17. Cole TJ, Bellizi MC, Flegal KM, Dietz WH. Establishing a standard definition for child overweight and obesity worldwide: international survey. BMJ. 2000;320:1240-1243. PubMed doi:10.1136/bmj.320.7244.1240

18. Tanner JM, Whitehouse RH. Clinical longitudinal standards for height, weight, height velocity and stages of puberty. Arch Dis Child. 1976;51:170-179. PubMed doi:10.1136/adc.51.3.170

19. Ruiz JR, Ramirez-Lechuga J, Ortega FB, et al. Artificial neural network-based equation for estimating VO2max from the $20 \mathrm{~m}$ shuttle run test in adolescents. Artif Intell Med. 2008;44:233-245. PubMed doi:10.1016/j.artmed.2008.06.004

20. Marfell-Jones M, Olds T, Stewart A, Carter L. International standards for anthropometric assessment. South Africa. Potchefstroom: ISAK; 2006.

21. Slaughter MH, Lohman TG, Boileau RA, et al. Skinfolds equations for estimation of body fatness in children and youth. Hum Biol. 1988;60:709-723. PubMed

22. Poortmans JR, Boisseau N, Moraine JJ, Moreno-Reyes R, Goldman $\mathrm{S}$. Estimation of total-body skeletal muscle mass in children and adolescents. Med Sci Sports Exerc. 2005;37:316-322. PubMed doi:10.1249/01.MSS.0000152804.93039.CE

23. Friedewald WT, Levy RI, Fredrickson DS. Estimation of the concentration of low-density lipoprotein cholesterol in plasma, without use of the preparative ultracentrifuge. Clin Chem. 1972;18:499-502. PubMed

24. O’Brien E, Asmar R, Beilin L, et al. Practice guidelines of the European Society of Hypertension for clinic, ambulatory and self blood pressure measurement. J Hypertens. 2005;23:697-701. PubMed doi:10.1097/01.hjh.0000163132.84890.c4

25. DeStefano RA, Caprio S, Fahey JT, Tamborlane WV, Goldberg B. Changes in body composition after a 12 -week aerobic exercise program in obese boys. Pediatr Diabetes. 2000;1:61-65. PubMed doi:10.1034/j.1399-5448.2000.010202.x

26. Runhaar J, Collard DC, Singh AS, Kemper HC, van Mechelen W, Chinapaw M. Motor fitness in Dutch youth: differences over a 26year period (1980-2006). J Sci Med Sport. 2010;13:323-328. PubMed doi:10.1016/j.jsams.2009.04.006

27. Adegboye A, Anderssen S, Froberg K, et al. Recommended aerobic fitness level for metabolic health in children and adolescents: a study of diagnostic accuracy. Br J Sports Med. 2011;45:722-728. PubMed doi:10.1136/bjsm.2009.068346

28. Angelopoulos PD, Milionis HJ, Grammatikaki E, Moschonis G, Manios Y. Changes in BMI and blood pressure after a school based intervention: the CHILDREN study. Eur J Public Health. 2009;19:319-325. PubMed doi:10.1093/eurpub/ckp004

29. Resaland GK, Anderssen SA, Holme IM, Mamen A, Andersen LB. Effects of a 2-year school-based daily physical activity intervention on cardiovascular disease risk factors: the Sogndal school-intervention study. Scand J Med Sci Sports. 2011;21:122131. PubMed doi:10.1111/j.1600-0838.2010.01181.x

30. Ben Ounis O, Elloumi M, Ben Chiekh I, et al. Effects of two-month physical-endurance and diet-restriction programs on lipid profiles and insulin resistance in obese adolescent boys. Diabetes Metab. 2008;34:595-600. PubMed doi:10.1016/j.diabet.2008.05.011

31. Collins CE, Okely AD, Morgan PJ, et al. Parent diet modification, child obesity, or both in obese children: An RCT. Pediatrics. 2011;127:619-627. PubMed doi:10.1542/peds.2010-1518

32. Cuenca-Garcia M, Ortega FB, Ruíz JR. Combined influence of healthy diet and active lifestyle on cardiovascular disease risk factors in adolescents. Scand J Med Sci Sports. 2014;24(3):55362. PubMed

33. Moreno LA, Sarria A, Popkin BM. The nutrition transition in Spain: a European Mediterranean country. Eur J Clin Nutr. 2002;56:9921003. PubMed doi:10.1038/sj.ejcn. 1601414

34. Royo-Bordonada MA, Gorgojo L, Martín-Moreno JM, et al. Investigators of the Four Provinces Study: Spanish children's diet: compliance with nutrient and food intake guidelines. Eur J Clin Nutr. 2003;57:930-939. PubMed doi:10.1038/sj.ejcn.1601627

35. Martínez-González MA, García-Arellano A, Toledo E, et al. A 14Item Mediterranean Diet Assessment Tool and Obesity Indexes among High-Risk Subjects: The PREDIMED Trial. PLoS One. 2012;7:e43134. PubMed doi:10.1371/journal.pone.0043134 
36. Bédard A, Dodin S, Corneau L, Lemieux S. The impact of abdominal obesity status on cardiovascular response to the Mediterranean diet. J Obes. 2012;2012:969124. PubMed

37. Ortega-Azorín C, Sorlí JV, Asensio EM, et al. Associations of the FTO rs9939609 and the MC4R rs17782313 polymorphisms with type 2 diabetes are modulated by diet, being higher when adherence to the Mediterranean diet pattern is low. Cardiovasc Diabetol. 2012;11:137. PubMed doi:10.1186/1475-2840-11-137

38. Maillot M, Issa C, Vieux F, Lairon D, Darmon N. The shortest way to reach nutritional goals is to adopt Mediterranean food choices: evidence from computer-generated personalized diets. Am J Clin Nutr. 2011;94:1127-1137. PubMed doi:10.3945/ajcn.111.016501

39. Lou-Bonafonte JM, Fitó M, Covas MI, Farràs M, Osada J. HDLrelated mechanisms of olive oil protection in cardiovascular disease. Curr Vasc Pharmacol. 2012;10:392-409. PubMed doi:10.2174/157016112800812827

40. Covas MI, Nyyssönen K, Poulsen HE, et al. The effect of polyphenols in olive oil on heart disease risk factors: a randomized trial. Ann Intern Med. 2006;5:333-341. PubMed doi:10.7326/0003-4819145-5-200609050-00006

41. Toledo E, Hu FB, Estruch R, et al. Effect of the Mediterranean diet on blood pressure in the PREDIMED trial: results from a randomized controlled trial. BMC Med. 2013;11:207. PubMed doi:10.1186/1741-7015-11-207

42. Ventura A, Birch L. Does parenting affect children's eating and weight status? Int J Behav Nutr Phys Act. 2008;5:15. PubMed doi:10.1186/1479-5868-5-15

43. Van Cauwenberghe E, Maes L, Spittaels H, et al. Effectiveness of school-based interventions in Europe to promote healthy nutrition in children and adolescents: systematic review of published and 'grey' literature. $B r \quad J$ Nutr. 2010;103:781-797. PubMed doi:10.1017/S0007114509993370 
Table 1 Characteristic of the Study Sample

\begin{tabular}{|c|c|c|c|c|c|c|}
\hline & $\begin{array}{c}C G \\
(N=41)\end{array}$ & $\begin{array}{c}P A \\
(N=28)\end{array}$ & $\begin{array}{c}N E \\
(N=21)\end{array}$ & $\begin{array}{l}\mathrm{PA}+\mathrm{NE} \\
(\mathrm{N}=25)\end{array}$ & $\begin{array}{c}\mathrm{PA}+\mathrm{NE}+\mathrm{EVOO} \\
(\mathrm{N}=20)\end{array}$ & $\begin{array}{c}\text { TOTAL } \\
(\mathrm{N}=135)\end{array}$ \\
\hline \multicolumn{7}{|l|}{ Sex } \\
\hline Male (\%) & $20(48.8)$ & $13(46.4)$ & $10(47.6)$ & $14(56)$ & $11(57.9)$ & $68(50.4)$ \\
\hline Female (\%) & $21(51.2)$ & $15(53.6)$ & $11(52.4)$ & $11(44)$ & $9(42.1)$ & $67(49.6)$ \\
\hline Age (years) $\pm \mathrm{SD}$ & $10.7 \pm 0.4$ & $10.6 \pm 0.5$ & $10.6 \pm 0.6$ & $10.7 \pm 0.6$ & $10.8 \pm 0.7$ & $10.7 \pm 0.5$ \\
\hline $\mathrm{BMI}\left(\mathrm{kg} / \mathrm{m}^{2}\right) \pm \mathrm{SD}$ & $20.9 \pm 4.1$ & $19.7 \pm 3.4$ & $17.8 \pm 2.3$ & $18.7 \pm 3.4$ & $19.7 \pm 3.5$ & $19.7 \pm 3.7$ \\
\hline $\begin{array}{l}\text { Fat \% (Slaughter) } \pm \\
\text { SD }\end{array}$ & $32.2 \pm 11.0$ & $29.7 \pm 8.4$ & $23.4 \pm 8.5$ & $27.9 \pm 8.8$ & $29.0 \pm 7.5$ & $29.02 \pm 9.30$ \\
\hline $\begin{array}{l}\text { Overweight/Obesity } \\
(\%)\end{array}$ & $21(51.2)$ & $11(39.2)$ & $5(23.8)$ & $8(32)$ & $8(40)$ & $53(39.3)$ \\
\hline $\mathrm{TC}(\mathrm{mg} / \mathrm{dl}) \pm \mathrm{SD}$ & $155.3 \pm 23.5$ & $159.9 \pm 23.3$ & $157.2 \pm 31.9$ & $154.9 \pm 22.5$ & $158.4 \pm 16.8$ & $156.7 \pm 24.8$ \\
\hline $\mathrm{TG}(\mathrm{mg} / \mathrm{dl}) \pm \mathrm{SD}$ & $89.7 \pm 20.7$ & $80.4 \pm 27.4$ & $80.0 \pm 28.8$ & $67.1 \pm 23.5$ & $78.9 \pm 34.3$ & $79.1 \pm 25.7$ \\
\hline $\mathrm{cHDL}(\mathrm{mg} / \mathrm{dl}) \pm \mathrm{SD}$ & $62.1 \pm 14.9$ & $52.6 \pm 12.3$ & $56.1 \pm 13.1$ & $50.9 \pm 10.9$ & $55.9 \pm 8.0$ & $56.0 \pm 12.8$ \\
\hline $\operatorname{cLDL}(\mathrm{mg} / \mathrm{dl}) \pm \mathrm{SD}$ & $81.06 \pm 17.3$ & $91.3 \pm 17.6$ & $84.1 \pm 20.9$ & $90.1 \pm 19.2$ & $87.7 \pm 13.4$ & $86.9 \pm 20.1$ \\
\hline
\end{tabular}

Abbreviations: TC, total cholesterol; TG, triglycerides; cHDL, cholesterol linked to high density lipoproteins; cLDL, cholesterol linked to low density lipoproteins; GG, control group; PA, physical activity group; NE, nutritional education group; PA+NE, physical activity + nutritional education group; EVOO, extra virgin olive oil; $\mathrm{PA}+\mathrm{NE}+\mathrm{EVOO}$, physical activity + nutritional education + EVOO group. 
Table 2 Changes Produced in the Body Profile and $\mathrm{VO}_{2}$ max in Different Groups After Intervention

\begin{tabular}{|c|c|c|c|c|c|c|c|c|c|c|}
\hline & \multicolumn{2}{|c|}{$\mathrm{CG}(\mathrm{Ns}=41)$} & \multicolumn{2}{|c|}{$\mathrm{PA}(\mathrm{Ns}=28)$} & \multicolumn{2}{|c|}{$\mathrm{NE}(\mathrm{Ns}=21)$} & \multicolumn{2}{|c|}{$\mathrm{PA}+\mathrm{NE}(\mathrm{Ns}=25)$} & \multicolumn{2}{|c|}{$\mathrm{PA}+\mathrm{NE}+\mathrm{EVOO}(\mathrm{Ns}=19)$} \\
\hline & Pretest & Posttest & Pretest & Posttest & Pretest & Posttest & Pretest & Posttest & Pretest & Posttest \\
\hline BMI $\left(\mathrm{kg} / \mathrm{m}^{2}\right) \pm \mathrm{SD}$ & $20.9 \pm 4.1$ & $21.1 \pm 4.0^{* *}$ & $19.7 \pm 3.4$ & $19.7 \pm 3.3$ & $17.8 \pm 2.3$ & $17.8 \pm 2.6$ & $18.7 \pm 3.4$ & $18.8 \pm 3.5$ & $19.7 \pm 3.5$ & $19.5 \pm 3.1$ \\
\hline Fat $\%$ (Slaughter) \pm SD & $32.2 \pm 11.0$ & $33.4 \pm 11.2^{*}$ & $29.7 \pm 8.4$ & $28.7 \pm 7.7^{*}$ & $23.4 \pm 8.5$ & $23.4 \pm 8.2$ & $27.9 \pm 8.8$ & $26.9 \pm 8.2^{*}$ & $29.0 \pm 7.5$ & $26.7 \pm 6.2 * *$ \\
\hline Mass \% (Poortmans) $\pm S D$ & $40.4 \pm 3.5$ & $40.8 \pm 3.8$ & $41.7 \pm 2.6$ & $42.3 \pm 2.8^{*}$ & $41.7 \pm 4.0$ & $42.1 \pm 4.6$ & $41.5 \pm 4.4$ & $42.7 \pm 4.4 * *$ & $41.5 \pm 4.1$ & $42.4 \pm 3.7^{*}$ \\
\hline Waist $(\mathrm{cm}) \pm \mathrm{SD}$ & $70.1 \pm 10.9$ & $69.6 \pm 10.0$ & $68.4 \pm 11.6$ & $65.8 \pm 9.6^{* *}$ & $62.0 \pm 5.6$ & $62.2 \pm 5.6$ & $64.5 \pm 8.2$ & $63.8 \pm 8.6$ & $69.4 \pm 7.9$ & $65.5 \pm 7.3^{* * *}$ \\
\hline $\mathrm{WHR} \pm \mathrm{SD}$ & $0.825 \pm 0.066$ & $0.815 \pm 0.053$ & $0.812 \pm 0.066$ & $0.787 \pm 0.050^{* *}$ & $0.814 \pm 0.033$ & $0.817 \pm 0.038$ & $0.803 \pm 0.053$ & $0.798 \pm 0.049$ & $0.851 \pm 0.037$ & $0.799 \pm 0.035^{* * *}$ \\
\hline$\Sigma 8$ Fold $(\mathrm{mm}) \pm \mathrm{SD}$ & $128.2 \pm 57.3$ & $133.7 \pm 60.4^{* *}$ & $114.2 \pm 49.2$ & $107.1 \pm 41.9^{* *}$ & $84.0 \pm 47.2$ & $82.7 \pm 47.1$ & $95.9 \pm 48.2$ & $91.0 \pm 52.8^{*}$ & $105.8 \pm 42.5$ & $97.1 \pm 34.9^{* *}$ \\
\hline $\operatorname{VO} 2 \max (\mathrm{ml} / \mathrm{kg} / \mathrm{min}) \pm \mathrm{SD}$ & $43.2 \pm 3.2$ & $43.2 \pm 3.8$ & $41.8 \pm 2.1$ & $43.8 \pm 3.1^{* * *}$ & $43.4 \pm 3.4$ & $43.6 \pm 4.5$ & $43.7 \pm 2.6$ & $45.7 \pm 4.2 * *$ & $42.9 \pm 3.0$ & $45.7 \pm 3.3^{* * *}$ \\
\hline
\end{tabular}

$*^{* *}, * * *$ : significant differences between Pretest-Posttest in different groups at the level of $P \leq .05, P \leq 001$, and $P \leq .001$ respectively.

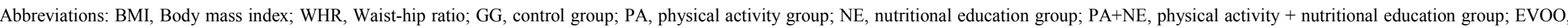
extra virgin olive oil; $\mathrm{PA}+\mathrm{NE}+\mathrm{EVOO}$, physical activity + nutritional education + EVOO group 
Table 3 Mean Differences Between Groups With 95\% Confidence Intervals

\begin{tabular}{|c|c|c|c|c|c|c|c|c|c|c|c|}
\hline & & \multicolumn{4}{|c|}{$C G$} & \multicolumn{3}{|c|}{ PA } & \multicolumn{2}{|r|}{$\mathrm{NE}$} & \multirow{2}{*}{$\begin{array}{c}\mathrm{PA}+\mathrm{NE} \\
\mathrm{PA}+\mathrm{NE}+\mathrm{EVOO}\end{array}$} \\
\hline & & PA & $\mathrm{NE}$ & $\mathrm{PA}+\mathrm{NE}$ & $\mathrm{PA}+\mathrm{NE}+\mathrm{EVOO}$ & $\mathrm{NE}$ & $\mathrm{PA}+\mathrm{NE}$ & $\mathrm{PA}+\mathrm{NE}+\mathrm{EVOO}$ & $\mathrm{PA}+\mathrm{NE}$ & $\mathrm{PA}+\mathrm{NE}+\mathrm{EVOO}$ & \\
\hline \multirow[t]{3}{*}{ BMI } & $\mathrm{MD}$ & .74 & $2.84^{*}$ & 1.82 & 1.10 & 1.11 & 1.08 & .37 & -1.03 & -1.74 & -.71 \\
\hline & MTE & .663 & .859 & .671 & .749 & .910 & .735 & .807 & .916 & .974 & .813 \\
\hline & IC & $(-1.09 ; 2.56)$ & $(.47 ; 5.21)$ & $(-.31 ; 3.66)$ & $(-.96 ; 3.16)$ & $(-.40 ; 4.61)$ & $(-.94 ; 3.10)$ & $(-1.85 ; 2.59)$ & $(-3.54 ; 1.49)$ & $(-4.42 ; .94)$ & $(-2.95 ; 1.52)$ \\
\hline \multirow[t]{3}{*}{ Fat $\%$} & MD & 3.10 & $8.86^{*}$ & $4.72 *$ & 4.47 & 5.76 & 1.63 & 1.37 & -4.14 & -4.39 & -.25 \\
\hline & MTE & 1.633 & 2.115 & 1.653 & 1.845 & 2.240 & 1.810 & 1.986 & 2.254 & 2.398 & 2.002 \\
\hline & IC & $(-1.40 ; 7.59)$ & $(3.04 ; 14.68)$ & $(.18 ; 9.27)$ & $(-.60 ; 9.54)$ & $(-.40 ; 11.92)$ & $(-3.95 ; 6.60)$ & $(-4.09 ; 6.84)$ & $(-10.33 ; 2.06)$ & $(-10.98 ; 2.21)$ & $(-5.76 ; 5.25)$ \\
\hline \multirow[t]{3}{*}{$\Sigma 8$ fold } & MD & 18.16 & $44.11^{*}$ & $31.08^{*}$ & 26.21 & 25.95 & 12.92 & 8.05 & -13.03 & -17.90 & -4.87 \\
\hline & MTE & 9.123 & 11.814 & 9.235 & 10.302 & 12.509 & 10.109 & 11.092 & 12.591 & 13.393 & 11.184 \\
\hline & IC & $(-6.92 ; 43.25)$ & $(11.62 ; 76.59)$ & $(5.68 ; 56.47)$ & $(-2.12 ; 56.54)$ & $(-8.45 ; 60.34)$ & $(-14.88 ; 40.71)$ & $(-22.45 ; 38.55)$ & $\begin{array}{c}(-47.65 ; \\
21.59)\end{array}$ & $(-54.72 ; 18.93)$ & $(-35.62 ; 25.89)$ \\
\hline \multirow[t]{3}{*}{ Waist } & MD & 2.54 & $7.22 *$ & $5.11^{*}$ & 1.65 & 4.68 & 2.57 & -.89 & -2.11 & -5.58 & -3.46 \\
\hline & MTE & 1.711 & 2.216 & 1.732 & 1.932 & 2.346 & 1.896 & 2.081 & 2.362 & 2.512 & 2.098 \\
\hline & IC & $(-2.17 ; 7.25)$ & $(1.13 ; 13.32)$ & $(.35 ; 9.87)$ & $(-3.67 ; 6.96)$ & $(-1.77 ; 11.14)$ & $(-2.64 ; 7.78)$ & $(-6.62 ; 4.83)$ & $(-8.61 ; 4.38)$ & $(-12.49 ; 1.33)$ & $(-9.23 ; 2.30)$ \\
\hline \multirow[t]{2}{*}{ DBP } & MD & -.05 & 3.28 & 3.17 & $6.19^{*}$ & 3.33 & 3.21 & 3.35 & -.12 & 2.91 & 3.03 \\
\hline & IC & $(-4.01 ; 3.92)$ & $(-2.00 ; 8.57)$ & $(-1.02 ; 7.35)$ & $(1.68 ; 10.71)$ & $(-2.08 ; 8.75)$ & $(-1.14 ; 7.57)$ & $(-1.57 ; 8.91)$ & $(-5.70 ; 5.46)$ & $(-2.92 ; 8.74)$ & $(-1.83 ; 7.89)$ \\
\hline \multirow[t]{3}{*}{ Glycaemia } & MD & 3.06 & -.16 & 1.34 & $6.37^{*}$ & -3.22 & -1.71 & 3.31 & 1.51 & 6.63 & 5.03 \\
\hline & MTE & 1.595 & 2.488 & 2.041 & 2.197 & 2.526 & 2.087 & 2.239 & 2.593 & 2.717 & 2.314 \\
\hline & IC & $(-2.33 ; 8.44)$ & $(-7.02 ; 6.69)$ & $(-4.28 ; 6.96)$ & $(.32 ; 12.42)$ & $(-10.18 ; 3.74)$ & $(-7.46 ; 4.03)$ & $(-2.86 ; 9.48)$ & $(-5.64 ; 8.65)$ & $(-.95 ; 14.02)$ & $(-1.35 ; 11.40)$ \\
\hline
\end{tabular}

* Significant differences at the level of $P \leq .05$.

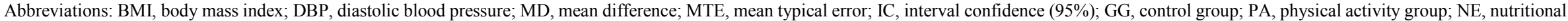
education group; PA+NE, physical activity + nutritional education group; EVOO, extra virgin olive oil; PA+NE+EVOO, physical activity + nutritional education + EVOO group. 
Table 4 Changes Produced in the Blood Profile and Comparison of Macronutrient Intake, Cholesterol, and Fiber in Different Groups After Intervention

\begin{tabular}{|c|c|c|c|c|c|c|c|c|c|c|}
\hline & \multicolumn{2}{|c|}{$C G(N=41)$} & \multicolumn{2}{|c|}{$\mathrm{PA}(\mathrm{N}=28)$} & \multicolumn{2}{|c|}{$\mathrm{NE}(\mathrm{N}=21)$} & \multicolumn{2}{|c|}{$\mathrm{PA}+\mathrm{NE}(\mathrm{N}=25)$} & \multicolumn{2}{|c|}{$\mathrm{PA}+\mathrm{NE}+\mathrm{EVOO}(\mathrm{N}=19)$} \\
\hline & Pretest & Posttest & Pretest & Posttest & Pretest & Posttest & Pretest & Posttest & Pretest & Posttest \\
\hline $\mathrm{SBP}(\mathrm{mmHg}) \pm \mathrm{SD}$ & $101.2 \pm 16.4$ & $104.2 \pm 15.7$ & $104.5 \pm 19.8$ & $98.2 \pm 14.1^{* *}$ & $98.3 \pm 9.1$ & $96.7 \pm 10.8$ & $98.0 \pm 11.7$ & $96.1 \pm 7.9$ & $102.6 \pm 11.0$ & $96.6 \pm 9.8^{* *}$ \\
\hline $\mathrm{DBP}(\mathrm{mmHg}) \pm \mathrm{SD}$ & $56.7 \pm 8.9$ & $59.6 \pm 7.9$ & $62.2 \pm 7.8$ & $57.9 \pm 8.4^{*}$ & $58.3 \pm 4.8$ & $58.6 \pm 7.0$ & $59.4 \pm 7.2$ & $53.7 \pm 4.7^{*}$ & $54.7 \pm 7.7$ & $52.7 \pm 4.7$ \\
\hline Glycaemia $(\mathrm{mg} / \mathrm{dl}) \pm \mathrm{SD}$ & $90.2 \pm 6.8$ & $93.3 \pm 8.5$ & $93.3 \pm 8.5$ & $80.4 \pm 17.7^{* *}$ & $91.08 \pm 10.8$ & $91.8 \pm 8.1$ & $93.9 \pm 9.8$ & $84.3 \pm 12.5^{*}$ & $88.5 \pm 9.6$ & $75.8 \pm 20.3^{*}$ \\
\hline $\mathrm{TC}(\mathrm{mg} / \mathrm{dl}) \pm \mathrm{SD}$ & $155.3 \pm 23.5$ & $168.3 \pm 28.3^{*}$ & $159.9 \pm 23.3$ & $148.3 \pm 29.3 * * *$ & $157.2 \pm 31.9$ & $148.7 \pm 32.3$ & $154.9 \pm 22.5$ & $139.0 \pm 17.5^{* * *}$ & $158.4 \pm 16.8$ & $145.3 \pm 31.6^{* * *}$ \\
\hline $\mathrm{cHDL}(\mathrm{mg} / \mathrm{dl}) \pm \mathrm{SD}$ & $62.1 \pm 14.9$ & $62.4 \pm 14.9$ & $52.6 \pm 12.3$ & $57.6 \pm 11.2$ & $56.1 \pm 13.1$ & $58.2 \pm 11.0$ & $50.9 \pm 10.9$ & $55.9 \pm 8.0$ & $54.6 \pm 11.3$ & $63.8 \pm 14.6^{*}$ \\
\hline $\operatorname{cLDL}(\mathrm{mg} / \mathrm{dl}) \pm \mathrm{SD}$ & $81.06 \pm 17.3$ & $87.06 \pm 21.4$ & $91.3 \pm 17.6$ & $78.3 \pm 19.8^{* * *}$ & $84.1 \pm 20.9$ & $76.9 \pm 23.9$ & $90.1 \pm 19.2$ & $70.3 \pm 13.7^{* * *}$ & $87.7 \pm 13.4$ & $72.9 \pm 25.5^{* *}$ \\
\hline $\mathrm{TG}(\mathrm{mg} / \mathrm{dl}) \pm \mathrm{SD}$ & $89.7 \pm 20.7$ & $86.4 \pm 19.1$ & $80.4 \pm 27.4$ & $70.0 \pm 28.3^{*}$ & $80.0 \pm 28.8$ & $67.5 \pm 25.4^{*}$ & $67.1 \pm 23.5$ & $68.6 \pm 20.3$ & $78.9 \pm 34.3$ & $69.1 \pm 26^{*}$ \\
\hline $\mathrm{E}(\mathrm{kcal}) \pm \mathrm{SD}$ & $1863 \pm 401$ & $1893 \pm 393$ & $1988 \pm 316$ & $1848 \pm 277$ & $2037 \pm 324$ & $1932 \pm 294$ & $2037 \pm 423$ & $1831 \pm 189^{* *}$ & $1966 \pm 341$ & $1982 \pm 279$ \\
\hline $\mathrm{CHO}(\%) \pm \mathrm{SD}$ & $47.1 \pm 5.7$ & $45.0 \pm 5.3$ & $47.3 \pm 4.7$ & $46.6 \pm 4.4$ & $44.8 \pm 4.6$ & $50.0 \pm 2.4^{* *}$ & $47.0 \pm 4.3$ & $48.9 \pm 2.6$ & $47.9 \pm 6.3$ & $50.9 \pm 3.6^{* *}$ \\
\hline Fats $(\%) \pm \mathrm{SD}$ & $37.8 \pm 4.7$ & $39.4 \pm 5.2$ & $36.9 \pm 4.7$ & $37.3 \pm 3.7$ & $38.9 \pm 5.22$ & $33.4 \pm 3.9^{* *}$ & $37.3 \pm 3.8$ & $35.5 \pm 2.1^{*}$ & $37.1 \pm 5.9$ & $34.6 \pm 3.9^{* *}$ \\
\hline $\operatorname{Prot}(\%) \pm \mathrm{SD}$ & $15.3 \pm 2.6$ & $15.8 \pm 2.3$ & $15.9 \pm 2.1$ & $16.4 \pm 2.3$ & $16.3 \pm 2.3$ & $16.4 \pm 2.2$ & $16.0 \pm 2.7$ & $15.3 \pm 1.8$ & $15.0 \pm 2.2$ & $14.5 \pm 2.6$ \\
\hline Fiber $(\mathrm{g}) \pm \mathrm{SD}$ & $11.1 \pm 3.6$ & $10.3 \pm 3.2$ & $11.0 \pm 2.5$ & $9.5 \pm 3.2$ & $13.2 \pm 4.2$ & $14.1 \pm 3.2$ & $12.8 \pm 4.0$ & $13.2 \pm 2.7$ & $11.2 \pm 2.9$ & $12.7 \pm 3.0$ \\
\hline
\end{tabular}

$*^{* *}, * * *$ Significant differences between pretest-posttest in different groups at the level of $P \leq .05, P \leq .001$, and $P \leq .0001$, respectively

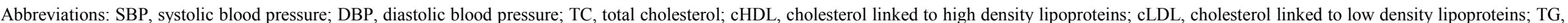

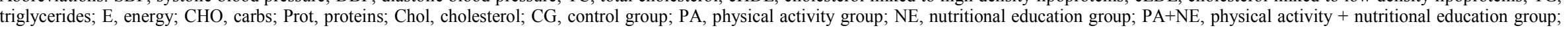
EVOO, extra virgin oil oil; PA+NE+EVOO, physical activity + nutritional education + EVOO group. 